\title{
BMJ Open Can a 3-hour educational workshop and the provision of practical tools encourage family physicians to prescribe physical activity as medicine? A pre-post study
}

\author{
Johann Windt, ${ }^{1,2}$ Adriaan Windt, ${ }^{3}$ Jennifer Davis, ${ }^{2,4}$ Robert Petrella, ${ }^{5}$ \\ Karim Khan ${ }^{1,2,6}$
}

To cite: Windt J, Windt A, Davis J, et al. Can a 3-hour educational workshop and the provision of practical tools encourage family physicians to prescribe physical activity as medicine? A pre-post study. BMJ Open 2015;5:e007920. doi:10.1136/bmjopen-2015007920

- Prepublication history for this paper is available online. To view these files please visit the journal online (http://dx.doi.org/10.1136/ bmjopen-2015-007920).

Received 10 February 2015 Revised 11 May 2015 Accepted 8 June 2015

CrossMark

For numbered affiliations see end of article.

Correspondence to Johann Windt; johann.windt@gmail.com

\section{ABSTRACT}

Objectives: To increase, in our sample, the proportion of family physicians who provided their patients with written physical activity prescriptions after the delivery of a 3-hour educational workshop with the provision of practical tools to facilitate behaviour change.

Design: A pre-post study.

Setting: Abbotsford and Mission, British Columbia. Participants: All 158 physicians registered with the Abbotsford (121) or Mission (37) Divisions of Family Practice were invited to participate.

Intervention: A 3-hour educational workshop combined with practical tools. Educational content of the workshop included (1) assessing patients' physical activity levels, (2) using motivational interviewing techniques to encourage physical activity and (3) providing written physical activity prescriptions when appropriate. Practical tools to facilitate physician behaviour changes included a 'physical activity vital sign', and copies of the Exercise is Medicine Canada Prescription Pad. Participating physicians completed a bespoke questionnaire before and 4 weeks after their attendance at the workshop.

Outcome measures: The primary outcome was the change in the proportion of family physicians who reported providing written physical activity prescriptions. Exploratory outcomes included changes in other physical activity prescription behaviours, the perceived importance of various barriers to prescription, and knowledge and confidence in regards to physical activity prescription. McNemar's test evaluated changes in proportions before and after the workshop, while Wilcoxon signed-rank tests evaluated changes in Likert data.

Results: 25 family physicians completed the baseline questionnaire and attended the workshop, with 100\% follow-up response rate. The proportion of family physicians who reported providing written physical activity prescriptions in their clinical practice increased significantly $(p<0.05)$, from $10(40 \%)$ at baseline to 17 $(68 \%) 4$ weeks after the intervention.

Conclusions: Educational workshops combined with practical tools appear to be a promising method to encourage the use of written physical activity

\section{Strengths and limitations of this study}

- This study's novelty, as this is the first study to document changes in family physicians' reported written physical activity prescription behaviours following an educational workshop. Since many have called for the development of medical school education and continuing education in the area of physical activity prescription, it is encouraging to see that such education may be effective in changing current family physician behaviours.

- The small sample size consisted of more male than female physicians, and was limited to two cities in southern British Columbia, Canada.

- Since all community physicians were invited, there was risk of self-selection bias, and there are inherent risks for inaccuracies when relying on self-reported data.

- The pre-post nature of the study lacks a control group for the intervention, and the 4-week follow-up does not indicate long-term behaviour change.

prescriptions among family physicians in this setting, over the short term.

\section{INTRODUCTION}

In 400 BC, Hippocrates wrote, 'Eating alone will not keep a man well; he must also take exercise'. ${ }^{1}$ Over two millennia later, physical inactivity has become a major public health problem; $31.1 \%$ of adults worldwide are physically inactive, ${ }^{2}$ and are therefore at increased risk of cardiovascular disease, stroke, hypertension, colon and breast cancers, type 2 diabetes, osteoporosis and allcause mortality. ${ }^{3-5}$ Primary care settings are considered an important public health investment $^{6}$ that may help address the current inactivity pandemic ${ }^{3}$ through the promotion of physical activity. 
Randomised controlled trials have shown that physical activity prescriptions increase patients' self-reported physical activity levels, ${ }^{7}$ improve quality of life, ${ }^{8}$ reduce body mass index and lower systolic blood pressure. ${ }^{9}$ Tailored interventions, including a written component, may have a greater effect on patient behaviour than brief advice alone, ${ }^{10} 11$ and have been preferred by physicians compared to verbal advice. ${ }^{12}$ Collectively, such trials have documented the efficacy of physical activity prescription for patient outcomes, but few investigations have looked to disseminate these findings into changing physicians' behaviour in real-world clinical practice.

The need for such dissemination is indicated, since just $16 \%$ of Canadian family physicians provide written physical activity prescriptions to their patients. ${ }^{13}$ The authors of this national survey suggested that the low frequency of written prescriptions indicated a need for targeted physician training. ${ }^{13}$ These low proportions are similar to those in the USA, where just one-third of patients report receiving any form of physical activity counselling from their physician in the last year. ${ }^{14}$

Physicians commonly cite lack of time, lack of education or knowledge, lack of compensation, and lack of tools or resources, as barriers to physical activity prescription. ${ }^{15-18}$ Addressing these common barriers by providing training and tools may be a key step in the dissemination of physical activity prescription into routine primary care practice. Moreover, family physicians are more likely to have higher self-efficacy regarding physical activity prescription and prescribe physical activity more frequently if they have received relevant training/education, ${ }^{19}{ }^{20}$ and if they themselves engage in frequent physical activity. ${ }^{21}$

The RE-AIM framework has been suggested for the evaluation of large-scale dissemination studies. ${ }^{22}$ It details five dimensions which together contribute to the public health impact of an intervention. These dimensions are (1) reach (at an individual level, per cent and representativeness of the target population that participates in the intervention), (2) efficacy/effectiveness (at an individual level extent to which the intervention achieves its desired outcome), (3) adoption (at an organisational level, per cent and representatives of settings that adopt an intervention), (4) implementation (at an organisational level, the degree to which the intervention is carried out as planned) and (5) maintenance (a measure of long-term behaviour change, at both the patient and organisation level). In our current clinician-targeted intervention, we focused our evaluation on the reach and effectiveness of the intervention at the individual physician level, and its level of implementation.

Specifically, we designed a 3-hour workshop aimed at (1) educating physicians on physical activity prescription and (2) providing them tools to facilitate these prescriptions in their practice. Reach was evaluated as the proportion of family physicians in our study population who chose to participate in the training intervention. Effectiveness was determined by evaluating pre-post survey results. Implementation was the fidelity of the delivered workshop to the original plan.

We hypothesised that the intervention would increase the proportion of family physicians providing patients with physical activity prescriptions. Our primary outcome was the proportion of family physicians who reported providing patients with written physical activity prescriptions. Exploratory outcomes included the change in (1) other physical activity prescription behaviours and the frequency with which they were performed, (2) perceived barriers to physical activity prescription and (3) knowledge and confidence as indicated by physicians' self-report and knowledge of the Canadian Physical Activity Guidelines.

\section{METHODS}

\section{Study design}

We used a single sample, pre-post study design with data collected at baseline and 1 month after the intervention.

\section{Subjects}

Our study sample included family physicians practicing in the municipalities of Abbotsford (124000 residents) and Mission (38000 residents), neighbouring cities in southern British Columbia, Canada. Potential participants were identified through their registration with the Abbotsford Division of Family Practice (121 members) or Mission Division of Family Practice (37 members). All registered members were invited to complete a physical activity prescription questionnaire and attend the educational workshop.

\section{Survey distribution}

The Abbotsford Division of Family Practice compiled the email and mailing addresses of the family physicians and completed the distribution of the surveys. One week prior to the distribution of the questionnaire, an introductory email detailed the study and invited physicians to participate when they received the mailed package. The baseline survey package was distributed in February 2014 to all 158 family physicians registered with the Divisions of Family Practice in Abbotsford, and Mission, British Columbia. It included a preaddressed, postagepaid return envelope, an informed written consent form, and the questionnaire. Follow-up emails were sent to all physicians 1 and 2 weeks after the original distribution. Finally, all family physicians who registered to attend the workshop were sent an additional reminder to complete the baseline questionnaire prior to attending.

One month after the workshop, the same survey delivery procedure was performed to deliver follow-up questionnaires to all physicians who filled out the baseline questionnaire and attended the workshop. The follow-up time of 1 month was chosen to maximise follow-up response rate while allowing for a period of time for 
physicians to incorporate changes to clinical behaviour following the workshop.

All participants were informed that participation was voluntary, and completed the informed written consent with the baseline survey.

\section{Survey instrument}

The bespoke five-page questionnaire consisted of 30 questions divided into five main sections, as detailed below. The survey took approximately $10 \mathrm{~min}$ for participants to complete. The survey was pretested with a number of medical residents and non-family physician professionals. Minor amendments were made based on pretesting feedback.

\section{Variables}

The survey included a brief section of demographic information (sex, age, years in practice, practice characteristics) before addressing five main sections related to physical activity prescription.

- Physical Activity Prescription Behaviours-Emulating Petrella and colleagues' national survey (2007), we inquired whether the physicians: (1) ask their patients about their physical activity levels, (2) assess the physical activity levels or physical fitness of their patients, (3) refer their patients to other healthcare providers for fitness assessments, (4) provide their patients with verbal physical activity counselling or (5) provide written physical activity prescriptions to their patients. Those who answered 'Yes' to any of these categories were then asked to specify the proportion of patients who performed that behaviour (1-20\%, 21-40\%, 41-60\%, 61-80\%, 81-100\%).

- Confidence and Knowledge. Physicians self-reported their perceived knowledge and confidence regarding physical activity prescription on a 10-point Likert scale $(1=$ not confident/knowledgeable, $10=$ extremely confident/knowledgeable), as well as listed the proportion of patients they believed would change their physical activity behaviours as a result of their counselling on a 5-point scale $(1-20 \%, 21-40 \%, 41-60 \%$, $61-80 \%, 81-100 \%)$.

- Perceived Barriers to Physical Activity Prescription: Physicians were asked to rank how important they perceived a list of 12 previously documented barriers to be in preventing them from prescribing physical activity more regularly ( $1=$ not important, $5=$ extremely important). ${ }^{17}$

- Knowledge of the Canadian Physical Activity Guidelines: Physicians were asked two multiple choice questions regarding (1) how many minutes of moderate physical activity/week $(60,90,160,300)$ and (2) how many days/week $(1,2,3,4+)$ of muscle and bone strengthening activities were recommended by the Canadian Physical Activity Guidelines. ${ }^{23}$

- Self-reported Physical Activity Levels: Physicians completed the short form of the International Physical Activity Questionnaire (IPAQ), a validated measure of self-reported physical activity levels based on previous 7-day recall. ${ }^{24}$ Their results were used to estimate their metabolic equivalent of task (MET) minutes/week and categorical activity level (low, moderate, high) as per the IPAQ scoring protocol..$^{25}$ According to the protocol, those in the 'Moderate' category obtain an equivalent of $30 \mathrm{~min}$ a day of physical activity on at least 5 days/week, which meets the recommended weekly activity for most public health guidelines.

\section{Workshop design, content and delivery}

The 3-hour workshop was primarily developed by two authors-one strength and conditioning specialist (JW) and one local family physician (AW). The primary aims of the workshop were to educate local family physicians on the value of physical activity prescriptions, and provide them with the tools to assess and prescribe physical activity efficiently and effectively in their clinical practice.

The workshop outlined three main steps for physicians to follow with patients: (1) assess patients' physical activity levels; (2) utilise patient-centred Motivational Interviewing techniques ${ }^{26}$ to change patients' physical activity behaviours and (3) provide written physical activity prescriptions to patients when appropriate. The health benefits of physical activity and the Canadian Physical Activity Guidelines were also presented. ${ }^{23}$ Workshops were interactive in nature, and case studies were utilised for practice purposes. Educational material delivered to the physicians included digital and print copies of workshop content, copies of the PAR-Q+ physical activity screening forms, ${ }^{27}$ as well as the Canadian Physical Activity Guidelines.

Finally, two primary tools were provided to physicians to facilitate the process of physical activity prescription. First, physicians were provided with a 'physical activity vital sign', ${ }^{28}{ }^{29}$ allowing them to quickly assess the physical activity levels of their patients. Second, they were given physical activity prescription pads, developed by the Exercise is Medicine Canadian Taskforce. ${ }^{30}$

Physicians attended one of two identical workshops that were delivered on two consecutive Fridays in April 2014, led by AW. No booster sessions, reminders or other follow-up training sessions were provided.

\section{RE-AIM evaluation}

Reach is defined as the percentage and representativeness of eligible individuals that agree to participate. In this study, it was simply the percentage of registered, eligible physicians who attended the training workshop.

In the RE-AIM framework, "E" can stand for either efficacy or effectiveness. Since our intervention was delivered in a real-world setting for family physicians, effectiveness is more appropriate. This was the primary indicator evaluated in this study, as it examines the degree to which the intervention had its desired effect of changing physicians' behaviours. We used the results 
of the pre-post survey to describe the effectiveness of our intervention.

Adoption refers to the level and representativeness of uptake at an organisational level, which we did not evaluate in our current investigation, focusing instead on individual physician behaviour.

Implementation is the degree to which an intervention was delivered as originally intended, and is usually evaluated at the organisational level. In our current investigation, implementation was described as the level to which the training workshop was delivered as planned.

Finally, maintenance refers to long-term change in behaviour, both in patients and providers. Owing to the short duration of follow-up, maintenance was not evaluated in this present study.

\section{Statistical analysis}

Calculations for the required sample size of this study were conducted based on changes in the proportion of physicians prescribing physical activity in written format, as indicated by McNemar's test for paired proportions. In order to achieve a power of 0.80 , with $\alpha=0.05$, and to observe a change in proportions of at least $0.25,{ }^{31} 29$ participants were required.

Basic descriptive analysis was performed in Microsoft Excel (Microsoft Office, 2013 Edition). All statistical tests were performed using $\mathrm{R}$ (Development Core Team, 2011).

Frequency distributions were carried out for all demographic and outcome variables. We used McNemar's $\chi^{2}$ test for paired data for primary outcome analysis to determine whether there was a significant change in the proportion of family physicians providing written physical activity prescription before and after the intervention. ${ }^{32}$ Our investigation also investigated a number of exploratory outcomes. McNemar's test evaluated the changes in binomial data before and after the intervention. Wilcoxon signed-rank tests assessed changes in paired five-point Likert data before and after the workshop, including the frequency of prescription behaviours as well as changes in perceived barriers. They were also used to measure changes in self-reported physical activity levels before and after the intervention. Finally, paired $\mathrm{t}$ tests assessed changes in self-reported knowledge and confidence. ${ }^{32}$ All analyses were performed with a significance level of 0.05 .

\section{RESULTS}

\section{Responder characteristics}

Thirty-three physicians attended the workshop. Of these, 26 filled out the baseline questionnaire prior to attending. An additional 15 physicians completed the baseline questionnaire but did not attend the workshop. One individual was excluded from the study as he was no longer practicing family medicine, leaving 25 family physicians eligible for inclusion. Of these, 21 were male
$(84 \%)$, and 4 were female $(16 \%)$. The average age of participants was $51.3( \pm 11.0$, range $=31-70)$ years, and average years in practice was $23.3( \pm 11.4$, range $=1-43)$. At baseline, 19 family physicians personally met the Canadian Physical Activity Guidelines. Follow-up questionnaires were received from all 25 family physicians $(100 \%)$.

\section{Reach}

Of 158 physicians who were invited to the training workshops, $33(21 \%)$ attended. Data for those who did not complete the baseline questionnaire and attend the workshop was not available, so the representativeness of the attendees in relation to our specific study population in Abbotsford and Mission could not be evaluated. When compared with the 2014 National Physician Survey, ${ }^{33}$ the mean age of our study sample (51.3) was similar to the national average (50.9), while the $\%$ of male physicians $(86 \%)$ in our study was higher than the national average $(56 \%)$.

\section{Effectiveness}

\section{Physical Activity Prescription Behaviours}

The proportion of family physicians who provided written physical activity prescriptions increased significantly from $10(40 \%)$ before the intervention, to 17 $(68 \%) 1$ month after the intervention $(\mathrm{p}<0.05)$ (figure 1 and table 1).

Significant increase was also seen in the proportion of physicians who reported referring patients for the purpose of physical activity assessment or appraisal, from $9(36 \%)$ to $16(64 \%) \quad(p<0.01)$. More physicians assessed their patients' physical activity levels after the intervention $(52-76 \%)$, although this was not significant $(p=0.13)$. There were no changes in the number of physicians who asked their patients about their physical activity levels or gave verbal counselling to their patients, as $100 \%$ of participating physicians reported engaging in these behaviours both before and after the workshop.

Physicians who responded 'Yes' to performing any of these behaviours were asked to describe the frequency with which they did so by categorising the percentage of patients $(1-20,21-40,41-60,61-80,81-100)$ with whom they performed each action. Table 2 details these frequencies before and after the workshop for physicians who engaged in each of the five behaviours at baseline. Among these physicians, there was a significant increase in the percentage of patients whom physicians asked (Wilcoxon signed-rank test, $\mathrm{p}<0.01$ ) and assessed (Wilcoxon signed-rank test, $\mathrm{p}<0.05$ ) in regards to physical activity.

\section{Barriers to Physical Activity Prescription}

Physicians' categorised the perceived importance of a number of common barriers to physical activity prescription before and after the workshop (table 3). The most common barrier to physical activity prescription was lack of time, with $76 \%$ of physicians reporting it as 
Figure 1 Proportion of family physicians engaging in five specific physical activity prescription behaviours preintervention and postintervention.

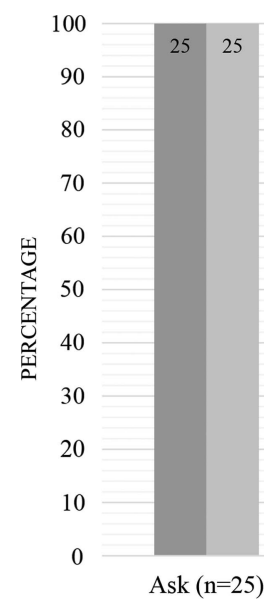

Ask $(\mathrm{n}=25)$

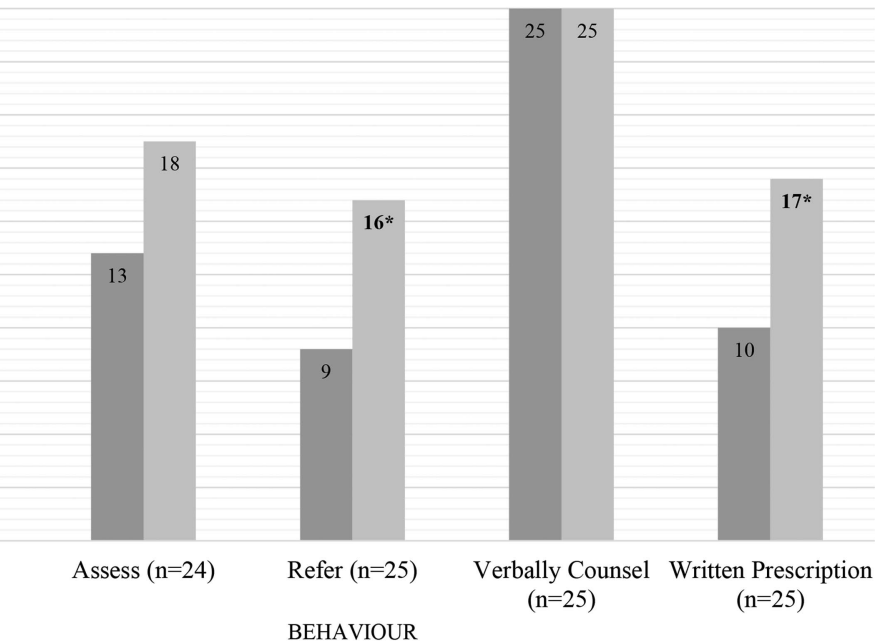

- Pre-Intervention (\%) $\quad$ - Post-Intervention (\%)
'Important', 'Very Important' or 'Extremely Important' before the workshop, which increased to $84 \%$ after the workshop. Prior to the workshop, the next important barriers were lack of tools, lack of education, and lack of continuing education, with more than 64\% regarding these as $\geq$ 'Important'.

After the workshop, the most significant barriers were reported as time, education, continuing education and financial incentive.

One month after the workshop, there was a significant decrease in the perceived importance of tools as a barrier to physical activity prescription $(\mathrm{p}<0.05)$. There was also a significant increase in the perceived importance of receiving no incentive $(\mathrm{p}<0.05)$ for physical activity prescription. The number of physicians ranking lack of education, lack of knowledge, lack of continuing education, and lack of guidelines all appeared to decrease, though none of these changes were significant.

\section{Self-reported knowledge and confidence levels}

Physicians' self-reported confidence and knowledge were significantly correlated with one another before (Pearson $r=0.84$ ) and after (Pearson $r=0.95$ ) the intervention. There was a significant increase in selfreported knowledge $(p<0.01)$ and confidence $(p<0.01)$ 1 month after the intervention. However, there was no significant change in the proportion of patients physicians believed would change their behaviour as a result of their counselling $(p=0.83)$.

\section{Knowledge of Canadian Physical Activity Guidelines}

The number of physicians who were able to correctly identify the Canadian Physical Activity Guidelines for aerobic activity and resistance training increased significantly from $4(16 \%)$ to $13(52 \%) \quad(\mathrm{p}<0.01)$. More physicians correctly chose the aerobic guidelines than the strength guidelines both before (20 vs 5) and after (21 vs 13) the workshop.

\section{Self-reported Physical Activity}

The median MET-minutes/week for physicians based on their IPAQ responses was 1624 before, and 1704 MET-minutes/week 1 month after the intervention-this difference was not significant. At baseline, 19 of the physicians $(79 \%)$ were at least in the 'Moderate' category of the IPAQ scoring system, meaning they reached the

\section{Table 1 Physical activity prescription behaviours preintervention and postintervention}

\begin{tabular}{|c|c|c|c|}
\hline Behaviour & $\begin{array}{l}\text { Preintervention } \\
\text { n (\%) }\end{array}$ & $\begin{array}{l}\text { Postintervention } \\
\text { n (\%) }\end{array}$ & p Value \\
\hline Ask $(n=25)$ & $25(100)$ & $25(100)$ & 1.0 \\
\hline Assess $(n=24)$ & $13(54)$ & $18(75)$ & 0.13 \\
\hline Refer $(n=25)$ & $9(36)$ & $16(64)$ & $0.004^{\star}$ \\
\hline Verbally counsel $(n=25)$ & $25(100)$ & $25(100)$ & 1.0 \\
\hline Written prescription $(n=25)$ & $10(40)$ & $17(68)$ & $0.04^{*}$ \\
\hline \multicolumn{4}{|c|}{$\begin{array}{l}{ }^{*} p<0.05 \text {. } \\
\text { Ask—do physicians ask their patients about their physical activity levels? } \\
\text { Assess-do physicians assess the physical activity levels or physical fitness of their patients? } \\
\text { Refer-do physicians refer their patients to other healthcare providers for fitness assessments? } \\
\text { Verbally counsel-do physicians provide patients with verbal physical activity counselling? } \\
\text { Written prescription—do physicians provide patients with written physical activity prescriptions? }\end{array}$} \\
\hline
\end{tabular}


Table 2 The frequency with which each behaviour was used among physicians who engaged in the behaviour both before and after the intervention

\begin{tabular}{|c|c|c|c|c|c|c|}
\hline Behaviour & $\begin{array}{l}1-20 \% \\
n\end{array}$ & $\begin{array}{l}21-40 \% \\
n\end{array}$ & $\begin{array}{l}41-60 \% \\
\mathrm{n}\end{array}$ & $\begin{array}{l}61-80 \% \\
\mathrm{n}\end{array}$ & $\begin{array}{l}81-100 \% \\
n\end{array}$ & Difference ( $p$ value) \\
\hline \multicolumn{7}{|l|}{ Ask } \\
\hline Before $(n=25)$ & 3 & 4 & 9 & 6 & 3 & $0.008^{*}$ \\
\hline After $(n=25)$ & 2 & 1 & 11 & 7 & 4 & \\
\hline \multicolumn{7}{|l|}{ Assess } \\
\hline Before $(n=13)$ & 2 & 2 & 6 & 1 & 2 & $0.02^{\star}$ \\
\hline After $(n=13)$ & 0 & 1 & 6 & 4 & 2 & \\
\hline \multicolumn{7}{|l|}{ Refer } \\
\hline Before $(n=9)$ & 4 & 3 & 2 & 0 & 0 & 0.12 \\
\hline After $(n=9)$ & 3 & 3 & 1 & 2 & 0 & \\
\hline \multicolumn{7}{|l|}{ Verbally counsel } \\
\hline Before $(n=25)$ & 3 & 5 & 9 & 4 & 4 & 0.62 \\
\hline After $(n=25)$ & 3 & 4 & 10 & 7 & 1 & \\
\hline \multicolumn{7}{|c|}{ Written prescription } \\
\hline Before $(n=10)$ & 5 & 2 & 2 & 1 & 0 & 1.0 \\
\hline After $(n=10)$ & 5 & 2 & 1 & 2 & 0 & \\
\hline
\end{tabular}

recommended levels of physical activity set forth by the Canadian Physical Activity Guidelines. At follow-up, 21 $(84 \%)$ of the physicians obtained at least this level of activity (table 4).

\section{Implementation}

The small scale of our current investigation allowed very high levels of implementation at the intervention level. The study content was delivered by the same family physician (AW), on two consecutive weekends, with no adaptation of content between the deliveries.

\section{DISCUSSION}

We examined the reach, effectiveness and implementation of a brief clinician-targeted workshop to increase physical activity prescriptions by family physicians in Abbotsford and Mission, British Columbia. The reach of the intervention was $21 \%$, with 33 family physicians of 158 who were invited opting to participate in the training intervention. Given the brief 2-week time period over which the intervention was delivered, implementation of the intervention was high. We investigated the effectiveness of our intervention by evaluating pre-post survey data. Notably, we found an increase in the proportion-from $40 \%$ to $68 \%$ - of family physicians who reported providing written physical activity prescriptions to their patients.

Though many trials have examined the efficacy of physical activity prescription in controlled research environments, dissemination studies in real-world clinical settings are rare. Previous large-scale dissemination studies, such as the 10000 Steps Rockhampton Project ${ }^{10}$ have utilised the RE-AIM framework. They demonstrated high levels of GP uptake, reasonable implementation levels, and increased rates of patients in the community being counselled on physical activity compared against a comparison community. ${ }^{10}$ However, it may be noted that there was no increase in the self-reported rates of physical activity prescription by family physicians involved in their investigation. Compared with the Rockhampton Project, our intervention was much smaller in scale, and focused primarily on physician implementation of physical activity prescription in their routine clinical practice, and was able to demonstrate an increase in self-reported physical activity prescription.

To our knowledge, only one other study has recorded changes in physical activity prescription behaviour after a brief clinician-targeted training workshop. ${ }^{34}$ Carroll et als study differed in a number of ways. They investigated a smaller number of physicians $(n=10)$, their primary outcome was clinician use of the 5As Framework, as evaluated by change in patient-rated Physical Activity Exit Interview (PAEI) survey results, and the training intervention focused less on the provision of written prescriptions and emphasised the $5 \mathrm{~A}$ framework and community referrals. They noted a significant improvement in the use of the 5As framework immediately after the intervention, but not at 6-month follow-up..$^{34}$ Our current study extends their findings by demonstrating that a brief intervention can change a physician's written physical activity prescription behaviours a month after training.

\section{Barriers and facilitators to prescription}

It is possible that the provision of tools (Physical activity vital sign and EIM Canada's Exercise Prescription and Referral Tool) in conjunction with the educational intervention played an important role in increasing the proportion of physicians providing written prescriptions. Lack of tools was the only perceived barrier to prescription that decreased significantly 1 month after the intervention. Notably, it was the second most cited barrier at 
Table 3 Perceived importance of selected barriers to physical activity prescription

\begin{tabular}{|c|c|c|c|c|c|c|c|}
\hline Barrier & $\begin{array}{l}\text { Not } \\
\text { important } \\
1 \\
\text { n (\%) }\end{array}$ & $\begin{array}{l}\text { Somewhat } \\
\text { important } \\
2 \\
\mathrm{n}(\%)\end{array}$ & $\begin{array}{l}\text { Important } \\
\mathbf{3} \\
\mathrm{n}(\%) \\
\end{array}$ & $\begin{array}{l}\text { Very } \\
\text { important } \\
4 \\
\mathrm{n}(\%) \\
\end{array}$ & $\begin{array}{l}\text { Extremely } \\
\text { important } \\
5 \\
\mathrm{n}(\%) \\
\end{array}$ & $\begin{array}{l}\text { I+VIP+EIP } \\
\text { n (\%) }\end{array}$ & p Value \\
\hline \multicolumn{8}{|l|}{ Lack of time } \\
\hline Before $(n=25)$ & $3(12)$ & $3(12)$ & $5(20)$ & $8(32)$ & $6(24)$ & 76 & \multirow[t]{2}{*}{0.41} \\
\hline After $(n=25)$ & $2(8)$ & $2(8)$ & $5(20)$ & $10(40)$ & $6(24)$ & 84 & \\
\hline \multicolumn{8}{|l|}{ Lack of tools } \\
\hline Before $(n=24)$ & $2(8)$ & $5(21)$ & $10(42)$ & $6(25)$ & $1(4)$ & 71 & \multirow[t]{2}{*}{$0.01^{*}$} \\
\hline After $(n=25)$ & $8(32)$ & $7(28)$ & $4(16)$ & $6(24)$ & $0(0)$ & 40 & \\
\hline \multicolumn{8}{|l|}{ Lack of education } \\
\hline Before $(n=25)$ & $2(8)$ & $6(24)$ & $6(24)$ & $10(40)$ & $1(4)$ & 68 & \multirow{2}{*}{0.44} \\
\hline After $(n=25)$ & $6(24)$ & $3(12)$ & $7(28)$ & $7(28)$ & $7(28)$ & 64 & \\
\hline \multicolumn{8}{|c|}{ Lack of continuing education } \\
\hline Before $(n=25)$ & $1(4)$ & $8(32)$ & $6(24)$ & $8(32)$ & $2(8)$ & 64 & \multirow[t]{2}{*}{0.34} \\
\hline After $(n=25)$ & $7(28)$ & $3(12)$ & $5(20)$ & $8(32)$ & $2(8)$ & 60 & \\
\hline \multicolumn{8}{|c|}{ Patients not interested } \\
\hline Before $(n=25)$ & $4(16)$ & $6(24)$ & $12(48)$ & $1(4)$ & $2(8)$ & 60 & \multirow[t]{2}{*}{0.72} \\
\hline After $(n=25)$ & $4(16)$ & $9(36)$ & $8(32)$ & $3(12)$ & $1(4)$ & 48 & \\
\hline \multicolumn{8}{|c|}{ Patients prefer pharmaceuticals } \\
\hline Before $(n=25)$ & $2(8)$ & $8(32)$ & $8(32)$ & $4(16)$ & $3(12)$ & 60 & \multirow[t]{2}{*}{0.51} \\
\hline After $(n=25)$ & $4(16)$ & $8(32)$ & $4(16)$ & $8(32)$ & $1(4)$ & 52 & \\
\hline \multicolumn{8}{|l|}{ Lack of guidelines } \\
\hline Before $(n=25)$ & $3(12)$ & $7(28)$ & $7(28)$ & $5(20)$ & $3(12)$ & 60 & \multirow[t]{2}{*}{0.12} \\
\hline After $(n=25)$ & $7(28)$ & $4(16)$ & $8(32)$ & $6(24)$ & $0(0)$ & 56 & \\
\hline \multicolumn{8}{|l|}{ Lack of knowledge } \\
\hline Before $(n=25)$ & $4(16)$ & $9(36)$ & $8(32)$ & $4(16)$ & $0(0)$ & 48 & \multirow[t]{2}{*}{0.45} \\
\hline After $(n=25)$ & 7 (28) & $9(36)$ & $5(20)$ & $3(12)$ & $1(4)$ & 36 & \\
\hline \multicolumn{8}{|l|}{ Lack of incentive } \\
\hline Before $(n=25)$ & $8(32)$ & $5(20)$ & $8(32)$ & $4(16)$ & $0(0)$ & 48 & \multirow[t]{2}{*}{$0.02^{*}$} \\
\hline After $(n=25)$ & $5(20)$ & $5(20)$ & $7(28)$ & $6(24)$ & $2(8)$ & 60 & \\
\hline \multicolumn{8}{|c|}{ Patients won't change } \\
\hline Before $(n=25)$ & $4(16)$ & $10(40)$ & $6(24)$ & $3(12)$ & $2(8)$ & 44 & \multirow[t]{2}{*}{0.12} \\
\hline After $(n=25)$ & $7(28)$ & $10(40)$ & $6(24)$ & $1(4)$ & $1(4)$ & 32 & \\
\hline \multicolumn{8}{|c|}{ Other changes more important } \\
\hline Before $(n=24)$ & $9(38)$ & 7 (29) & $5(21)$ & $1(4)$ & $2(8)$ & 33 & \multirow[t]{2}{*}{0.10} \\
\hline After $(n=25)$ & $14(56)$ & $4(16)$ & $4(16)$ & 3 (12) & $0(0)$ & 28 & \\
\hline \multicolumn{8}{|l|}{ Lack of evidence } \\
\hline Before $(n=25)$ & $18(72)$ & $3(12)$ & $0(0)$ & $4(16)$ & $0(0)$ & 16 & \multirow[t]{2}{*}{0.66} \\
\hline After $(n=25)$ & $17(68)$ & $3(12)$ & $1(4)$ & $2(8)$ & $2(8)$ & 20 & \\
\hline
\end{tabular}

Table 4 Family physicians' self-reported physical activity levels

\begin{tabular}{|c|c|c|}
\hline & $\begin{array}{l}\text { Preintervention } \\
(n=24)\end{array}$ & $\begin{array}{l}\text { Postintervention } \\
(\mathrm{n}=25)\end{array}$ \\
\hline $\begin{array}{l}\text { MET minutes } \\
\text { (median (IQR)) }\end{array}$ & $1624(1026-2335)$ & $1704(1011-2542)$ \\
\hline Low (n (\%)) & $5(21)$ & $4(16)$ \\
\hline Moderate (n (\%)) & $10(42)$ & $10(40)$ \\
\hline High (n (\%)) & 9 (37) & $11(44)$ \\
\hline \multicolumn{3}{|c|}{$\begin{array}{l}\text { Low=Reported no physical activity or not enough to reach } \\
\text { 'Moderate' category. } \\
\text { Moderate=Equivalent to at least } 5 \text { days of activity with at least } \\
30 \text { min of activity on those days. Enough reported activity to reach } \\
\text { public health recommendations. } \\
\text { High=A third category of physical activity associated with } \\
\text { increased health benefits, equivalent to an hour of moderate } \\
\text { activity daily. }\end{array}$} \\
\hline
\end{tabular}

baseline, and only the eighth most important barrier after the intervention. This finding encourages the provision of specific tools as a supplement to education alone. Further, the preference of physicians for tailored written prescriptions over verbal advice alone in the successful Green Prescription programme further supports the use of tools to facilitate physician behaviour change. ${ }^{12}$

Education and related factors have been repeatedly cited as barriers to the implementation of physical activity prescription. ${ }^{17} 18$ Physicians who report having received education, or have a higher self-efficacy regarding physical activity prescription, are more likely to engage in these behaviours with their patients, ${ }^{19}{ }^{20}$ as $73 \%$ of US physicians feel there is a need for further education regarding physical activity prescription, ${ }^{35}$ and among 4th-year medical students at the University of 
British Columbia, $86 \%$ thought their training in physical activity prescription was inadequate, ${ }^{36}$ The perceived barriers of education and knowledge can also be seen in lack of guideline knowledge.

Our current data indicate a lack of knowledge of physical activity guidelines, seen in the low proportion of physicians $(16 \%)$ who were able to correctly identify the Canadian Physical Activity Guidelines prior to the workshop. Similarly, only $23 \%$ of US physicians were familiar with the American College of Sports Medicine Guidelines. ${ }^{35}$ Our results show that providing continuing education may facilitate improvements in perceived knowledge and confidence of family physicians to prescribe physical activity. A significantly greater proportion of physicians were familiar with the Canadian Physical Activity Guidelines after the intervention. However, though the perceived importance of lack of standard guidelines, education, knowledge and continuing education all decreased, none of these were significant.

Family physicians' physical activity prescription behaviours are also associated with their own personal physical activity levels. ${ }^{37}$ In our study, the majority of physicians, $79 \%$ at baseline and $84 \%$ at follow-up, were at least moderately active, accumulating the recommended levels of physical activity by the Canadian guidelines. This may help to explain why the baseline levels of all the physical activity prescription behaviours were higher than in previous cross-sectional studies. ${ }^{13} 17$

Lack of time was the most significant barrier to physical activity prescription-a common finding in physician surveys. ${ }^{16-18}$ This did not change after the workshop. The only barrier that increased significantly in perceived importance was lack of financial incentive. For physical activity prescriptions to become more common, it may be important that physicians receive training on how to prescribe in a time-efficient manner, or receive reimbursement that compensates them for the additional time spent performing physical activity counselling with their patients.

\section{Strengths and limitations}

To our knowledge, this is the first study to report a change in family physicians' use of written physical activity prescriptions before and after a brief cliniciantargeted intervention. Second, it investigates the effectiveness of a real-world intervention that aimed at changing clinical practice, which is less commonly reported in the literature. Third, the smaller scale and short time period of the study allowed for high levels of implementation in delivering the training. Finally, the intervention was not solely based on education, but provided practical tools that facilitated the targeted change, and significantly reduced this as a perceived barrier to physical activity prescription.

The present study has some limitations, including its single-group, pre-post study design, and relatively small sample size of 25, below the power calculation of 29 . Not all indicators of the RE-AIM framework were investigated, as the short-term follow-up prevented evaluation of maintenance, and the targeted of individual physicians preventing the evaluation of adoption. Further, the lack of data on non-responders prevented a full examination of the representativeness of participating physicians with the local population. The external validity of the study is a limitation, as we invited physicians from only two cities in Western Canada. Finally, the effectiveness of the educational workshops and written materials may have been enhanced by a more comprehensive intervention and maintenance encouraged with follow-up sessions and reminders. ${ }^{38}$

Owing to the reliance on self-reported data for behaviour, there was an inherent risk for response bias. Since all physicians in the two municipalities were invited, there was a risk of self-selection bias, with more motivated physicians choosing to attend. The physicians who attended the workshop demonstrated a lack of baseline knowledge regarding physical activity guidelines, but most were physically active themselves. It may be that the workshop attracted those who were in need of further education, but were personally invested in the area of physical activity.

\section{Future directions}

Dissemination investigations with increased sample size and comparison designs are needed. It is recommended that more objective measurements be used to assess clinician behaviour, such as direct observation or audio recordings of consultations. ${ }^{39}$ Ideally, long-term ( $>2$ year) trials should investigate whether cliniciantargeted interventions lead to patient behaviour and health outcome change, in addition to physician behaviour change. This would allow for all parameters of the RE-AIM framework to be evaluated, and the public health impact of such interventions to be effectively quantified.

The results of this study indicate that providing family physicians with training and tools may be an important component in effectively implementing physical activity prescription into routine clinical practice, and should be considered in future dissemination trials.

We conclude that physician training workshops combined with practical tools provide a promising method of encouraging physical activity prescriptions in this type of setting.

\section{Author affiliations}

${ }^{1}$ Department of Experimental Medicine, University of British Columbia, Vancouver, Canada

${ }^{2}$ Centre for Hip Health and Mobility, University of British Columbia, Vancouver, Canada

${ }^{3}$ Department of Family Medicine, University of British Columbia, Vancouver, Canada

${ }^{4}$ Department of Population \& Public Health, University of British Columbia, Vancouver, Canada

${ }^{5}$ Department of Family Medicine, Schulich School of Medicine, University of Western Ontario, London, Canada

${ }^{6}$ Aspetar Orthopedic and Sports Medicine Hospital, Doha, Qatar 
Acknowledgements The authors would like to acknowledge the support of the BC Ministry of Health for physical activity promotion work in the Province of British Columbia.

Contributors All authors were responsible for study concept and design. AW and JW were primarily responsible for designing the educational workshop. $\mathrm{JD}$ and JW were responsible for the analysis of the study data. All authors contributed to writing and critical revision of the manuscript.

Funding JW is funded by a graduate award by the Canadian Institutes of Health Research. AW is funded by the Clinician Scholar Program scholarship through the University of British Columbia. JD is funded by the Michael Smith Foundation for Health Research Postdoctoral Fellowship Award and the Canadian Institute for Health Research Postdoctoral Fellowship Award.

Competing interests None declared

Ethics approval The study was approved by the Behavioural Research Ethics Board at the University of British Columbia (H13-01977) and by the Fraser Health Authority Research Ethics Board (2014-013).

Provenance and peer review Not commissioned; externally peer reviewed.

Data sharing statement All the data for the study are housed at the Centre for Hip Health and Mobility, in Vancouver BC. Only team members have access to the raw data for the sole purpose of dissemination of the results. Data analysis is ongoing.

Open Access This is an Open Access article distributed in accordance with the Creative Commons Attribution Non Commercial (CC BY-NC 4.0) license, which permits others to distribute, remix, adapt, build upon this work noncommercially, and license their derivative works on different terms, provided the original work is properly cited and the use is non-commercial. See: http:// creativecommons.org/licenses/by-nc/4.0/

\section{REFERENCES}

1. Hippocrates. Regimen I. Translated by W.H.S Jones. Cambridge: Harvard University Press, 1953:229.

2. Hallal PC, Andersen LB, Bull FC, et al. Global physical activity levels: surveillance progress, pitfalls, and prospects. Lancet 2012;380:247-57.

3. Kohl HWIII, Craig CL, Lambert EV, et al. The pandemic of physical inactivity: global action for public health. Lancet 2012;380:294-305.

4. Warburton DE, Charlesworth S, Ivey A, et al. A systematic review of the evidence for Canada's Physical Activity Guidelines for adults. Int J Behav Nutr Phys Act 2010;7:39.

5. Warburton DE, Nicol CW, Bredin SSD. Health benefits of physical activity: the evidence. Can Med Assoc J 2006;174:801-9.

6. Global Advocacy for Physical Activity (GAPA) the Advocacy Council of the International Society for Physical Activity and Health (ISPAH). Investments that work for physical activity. $\mathrm{Br} J$ Sports Med 2012;46:709-12.

7. Orrow G, Kinmonth AL, Sanderson S, et al. Effectiveness of physical activity promotion based in primary care: systematic review and meta-analysis of randomised controlled trials. BMJ 2012;344(mar26 1):e1389.

8. Kallings LV, Leijon M, Hellénius M-L, et al. Physical activity on prescription in primary health care: a follow-up of physical activity level and quality of life. Scand J Med Sci Sports 2008;18:154-61.

9. Petrella RJ, Koval JJ, Cunningham DA, et al. Can primary care doctors prescribe exercise to improve fitness? The step test exercise prescription (STEP) project. Am J Prev Med 2003;24:316-22.

10. Eakin EG, Glasgow RE, Riley KM. Review of primary care-based physical activity intervention studies: effectiveness and implications for practice and future research. J Fam Pract 2000;49:158-68.

11. Petrella RJ, Lattanzio CN. Does counseling help patients get active? Systematic review of the literature. Can Fam Physician 2002;48:72-80.

12. Swinburn BA, Walter LG, Arroll B, et al. Green prescriptions: attitudes and perceptions of general practitioners towards prescribing exercise. Br J Gen Pract 1997;47:567-9.

13. Petrella RJ, Lattanzio CN. Physical activity counseling and prescription among Canadian primary care physicians. Arch Intern Med 2007;167:1774-81.
14. Barnes PM, Schoenborg CA. Trends in adults receiving a recommendation for exercise or other physical activity from a physician or other health professional. Hyattsville, MD: National Center for Health Statistics [Internet], 2012. [cited 8 Oct 2014]; no. 86. 7p. http://www.cdc.gov/nchs/data/databriefs/db86.pdf

15. Douglas F, Torrance N, van Teijlingen E, et al. Primary care staff's views and experiences related to routinely advising patients about physical activity. A questionnaire survey. BMC Pub Health 2006;6:138.

16. Hébert ET, Caughy MO, Shuval K. Primary care providers' perceptions of physical activity counselling in a clinical setting: a systematic review. Br J Sports Med 2012;46:625-31.

17. Kennedy MF, Meeuwisse W. Exercise counselling by family physicians in Canada. Prev Med 2003;37:226-32.

18. McKenna J, Naylor PJ, McDowell N. Barriers to physical activity promotion by general practitioners and practice nurses. $\mathrm{Br} J$ Sports Med 1998;32:242-7.

19. Howe M, Leidel A, Krishnan SM, et al. Patient-related diet and exercise counseling: do providers' own lifestyle habits matter? Prev Cardiol 2010;13:180-5.

20. Jorgensen TK, Nordentoft M, Krogh J. How do general practitioners in Denmark promote physical activity? Scand. J Prim Health Care 2012;30:141-6.

21. Frank E, Segura C. Health practices of Canadian physicians. Can Fam Physician 2009;55:810-11.e7.

22. Glasgow RE, Vogt TM, Boles SM. Evaluating the public health impact of health promotion interventions: the RE-AIM framework. Am J Public Health 1999;89:1322-7.

23. Canadian Society for Exercise Physiology. CSEP—Get the Guidelines [Internet]. [cited 15 Oct 2014]. http://www.csep.ca/ english/view.asp? $\mathrm{x}=804$

24. Craig CL, Marshall AL, Sjöström M, et al. International physical activity questionnaire: 12 -country reliability and validity. Med $S c i$ Sports Exerc 2003;35:1381-95.

25. Guidelines for data processing and analysis of the international physical activity questionnaire [Internet] 2005. [cited 13 Oct 2014]. http://www.ipaq.ki.se/scoring.pdf

26. Rollnick S, Miller WR, Butler C. Motivational interviewing in health care: helping patients change behaviour. Guilford Press, 2008:225.

27. Bredin SD, Gledhill N, Jamnik VK, et al. PAR-Q+ and ePARmed-X+. Can Fam Physician 2013;59:273-7.

28. Coleman $\mathrm{KJ}$, Ngor $\mathrm{E}$, Reynolds $\mathrm{K}$, et al. Initial validation of an exercise "vital sign" in electronic medical records. Med Sci Sports Exerc 2012;44:2071-6.

29. Sallis R. Developing healthcare systems to support exercise: exercise as the fifth vital sign. Br J Sports Med 2011;45:473-4.

30. Exercise is Medicine Canadian Taskforce. Exercise Prescription \& Referral Tool. Exercise is Medicine Canada. [cited 15 Oct 2014]. http://www.exerciseismedicine.ca/professional-resources/ exercise-prescription-referral-tool

31. Gunn J, Southern D, Chondros P, et al. Guidelines for assessing postnatal problems: introducing evidence-based guidelines in Australian general practice. Fam Pract 2003;20:382-9.

32. Pagano M, Gauvreau K. Principles of biostatistics. 2nd edn. Pacific Grove, CA: Duxbury Press, 2000:592.

33. The College of Family Physicians of Canada, Canadian Medical Association, The Royal College of Physicians and Surgeons of Canada. 2014 National Physician Survey. 2014. [cited 1 May 2015]. http://nationalphysiciansurvey.ca/wp-content/uploads/2014/11/ 2014-National-EN.pdf

34. Carroll JK, Winters PC, Sanders MR, et al. Clinician-targeted intervention and patient-reported counseling on physical activity. Prev Chronic Dis 2014:11:130302. [cited 2014 Sep 7]. http://www. cdc.gov/pcd/issues/2014/13_0302.htm.

35. Williford HN, Barfield BR, Lazenby RB, et al. A survey of physicians' attitudes and practices related to exercise promotion. Prev Med 1992:21:630-6.

36. Holtz KA, Kokotilo KJ, Fitzgerald BE, et al. Exercise behaviour and attitudes among fourth-year medical students at the University of British Columbia. Can Fam Physician 2013;59:e26-32.

37. Frank E, Segura C, Shen $\mathrm{H}$, et al. Predictors of Canadian physicians' prevention counseling practices. Can J Public Health Rev Can Santee Publique 2010;101:390-5.

38. Smith WR. Evidence for the effectiveness of techniques to change physician behaviour. Chest 2000;118(2 Suppl):8S-17S.

39. Carroll JK, Antognoli E, Flocke SA. Evaluation of physical activity counseling in primary care using direct observation of the 5As. Ann Fam Med 2011;9:416-22. 